\title{
"Keep it Sacred!": Indigenous Youth-Led Filmmaking to Advance Critical Race Media Literacy
}

\author{
Christine Rogers Stanton \\ Montana State University \\ U. S. A. \\ Brad Hall \\ University of Montana \\ U. S. A. \\ Veronica Willeto DeCrane \\ $21^{\text {st }}$ Century Community Learning Centers, \\ Montana Office of Public Instruction
}

U. S. A.

\begin{abstract}
Due to the influence of digital media, today's educators encounter unique challenges-and possibilities-surrounding efforts to advance civic dialogue and critical literacy. This case study, which focuses on two projects with rural Indigenous communities, describes student-led research and filmmaking as teaching pedagogy and research methodology within formal and informal educational spaces. Findings demonstrate the potential for Indigenous counter-narratives to support place conscious and culturally revitalizing media education; increased learner motivation through student-centered pedagogy, anti-colonial education, and civic engagement; and expanded intercultural dialogue and intergenerational understanding. The study offers implications for educators, researchers, and community partners.
\end{abstract}

KEYWORDS: Indigenous, Youth Participatory Action Research, Storywork, Critical Race Theory, Media Literacy

\author{
Background \\ Theoretical Framework \\ Methods \\ Results and Discussion \\ Significance and Implications: Advancing Reciprocity \\ Notes \\ References \\ Author Contact
}

\begin{abstract}
Since its inception, public education in the U.S. has marginalized or excluded perspectives of youth and people of color-especially those of
\end{abstract}


Indigenous ${ }^{1}$ peoples (Bautista et al., 2013; Beattie, 2012; Loewen, 2010; Mitra, 2008; Sanchez, 2007; Shear, Knowles, Soden, \& Castro, 2015). The resulting monocultural "whitewashed" educational narrative (Loewen, 2010) emboldens teachers, researchers, and curriculum developers to claim or imply a mythical "neutrality," instead of honestly and openly confronting bias, settler-colonialism, injustice, and inequity (Stanton, 2014). Furthermore, today's educators are unprepared to confront inaccurate curricular materials and their own misunderstandings about the experiences of peoples of color, because they often have limited familiarity with strategies to support classroom dialogue and critical thinking about complex issues such as racism and injustice (King \& Chandler, 2016).

This article explores ways student-led digital storywork, which partners students with Indigenous community members to learn-and teach-about cultural protocol, oral histories, and multimodal research methods, can advance pedagogical and methodological understandings of critical race media literacy. In the examples highlighted in this article, students chose research topics and participants, filmed interviews and collected supplemental material, analyzed project data, edited footage, and shared their projects with appropriate audiences and in appropriate contexts. The findings offer implications in terms of curricular (re)design, critical pedagogy, teacher education, and educational research methodology.

\section{Background}

Since time immemorial, Indigenous peoples have shared knowledge in community-centered and place-conscious ways. After the invasion of the lands now known as the Americas by Europeans, forced relocation and assimilative approaches to education were used in efforts to sever community and place-and the intertwined aspects of culture-from youth (Lomawaima, 2004). Treaties sought to rectify removal of Indigenous peoples from traditional homelands, to contain Indigenous nations, and to simplify the process of separating children from their families (Hixon, 2013). Beginning in the 1800s and reaching far into the 1900s, Indian boarding schools were used as tools of cultural oppression by religious and government entities (Haag, 2007). In many of these schools, traditional cultural practices and Indigenous languages were banned, and violators were punished severely. As a result, entire generations of Indigenous communities experienced a fragmentation of their histories.

Although boarding schools no longer exist with the main purpose to "kill the Indian and save the man" (Pratt, cited in Ostler, 2004, p. 151), educational systems in the U.S. continue to situate Indigenous peoples and their experiences as deficient, romanticized, and/or relegated to the distant past (Shear, et al., 2015; Stanton, 2014). Both content and pedagogy are negatively impacted by exclusion or misrepresentation of Indigenous experiences. In particular, social studies textbooks, standards, and other resources often misrepresent Indigenous 
histories, perspectives, and experiences (Loewen, 2010; Sanchez, 2007; Shear, et al., 2015).

Similarly, education has largely neglected youth perspectives (Bautista et al., 2013; Beattie, 2012; Mitra, 2008)—-thereby marginalizing the stakeholder group that should be most central in such work. Pedagogically, educators who rely on teacher-centered methods, which remain popular (Russell, 2010), promote "antidemocratic dispositions among students" (Knowles, 2018, p. 69). These "Western" approaches often conflict with Indigenous epistemologies (Brayboy, 2005; Grande, 2008; Kovach, 2009; Smith, 1999; Wilson, 2008). Therefore, Indigenous youth voice provides an exceptionally potent response to misrepresentations of Indigenous knowledges and ways of knowing (San Pedro, 2015; Tuck \& Yang, 2013).

\section{Theoretical Framework}

To address the pedagogical and methodological challenges within education and research, this study engages Tribal Critical Race Theory (TribalCrit) (Brayboy, 2005), Indigenous Research Methodologies (IRMs) (Grande, 2008; Kovach, 2009; Smith, 1999; Wilson, 2008), and Indigenous Storywork (Archibald, 2008). Although there is extensive diversity across and within Indigenous groups, these orientations generally support enhanced respect for Indigenous sovereignty, knowledges, and theories as shared through story and counter-narrative.

TribalCrit offers a framework both to view the history of Indigenous education and to critically evaluate the role of current and future educational efforts to reinforce or disrupt racial, social, and political injustices. As a theory related to Critical Race Theory (Ladson-Billings, 1999), TribalCrit advances many of the same understandings (e.g., racism is endemic; narratives of people of color must be elevated to counter white ${ }^{2}$ supremacist views). However, TribalCrit is unique in its attention to political nationhood, tribal sovereignty, and settler colonialism. As Sabzalian (2019) argues, schools have played a powerful role in erasing and delegitimizing Indigenous nationhood, despite its centrality to Indigenous identity.

Of particular importance to the study shared here, both Critical Race Theory and TribalCrit recognize that stories/counter-narratives are valid sources of scholarly and practical understanding. As Brayboy (2005) explains, "Stories are not separate from theory; they make up theory and are, therefore, real and legitimate sources of data and ways of being" (p. 430). Similarly, IRMs provide practical, methodological ways to enact theory, but they are not separate from Indigenous worldviews. While IRMs are not a set of standardized, prescriptive methods, they help articulate general understandings about the transfer of knowledge within Indigenous communities. For example, IRM scholars emphasize that to begin decolonizing research practice, researchers need to demonstrate deep appreciation for, and enactment of, meaningful and sustained relationships (Smith, 1999; Wilson, 2008). 
Indigenous storywork is an example of a specific approach to IRMs, and it offers additional guidance and structure for researchers and participants in terms of research practice (Archibald, 2008). Since storywork focuses on knowledge transfer between knowledge carriers and community members, including those who are students in $\mathrm{K}-12$ contexts, it can be viewed simultaneously as a theory, methodology, and pedagogy. As Hall (2018) explains of research within the Piikani community, "Theory and practice are not separate, but they are interconnected and continuously interacting with each other" (p. 380). In other words, storywork depends upon a deep understanding of community-specific worldviews, relationships, and other "situational awareness" (Hall, 2018, p. 380).

Together, the "theoretical" frameworks informing the study described in this article align well with several other areas of critical theory, methodology, and pedagogy, including Youth Participatory Action Research (YPAR) (Bautista et al., 2013; Caraballo, Lozenski, Lyiscott, \& Morrell, 2017), critical media pedagogy (Morrell, Duenas, Garcia, \& Lopez, 2013), and Culturally Sustaining and Revitalizing Pedagogy (McCarty \& Lee, 2014; Paris, 2012), to inform both the development and study of youth-led research projects. Broadly, critical scholars encourage purposeful attention to marginalized cultural knowledges within classrooms (González, Moll, \& Amanti, 2005; Paris, 2012), and they recognize the need to include youth and other members of marginalized communities as leaders in both research and practice.

In basic terms, YPAR engages youth in "opportunities to study social problems affecting their lives and then determine actions to rectify these problems" (Cammarota \& Fine, 2008, p. 2). As a particular model to enact YPAR, Morrell, Duenas, Garcia, and Lopez (2013) advocate for youth media production, which seeks to interrogate representations of power and knowledge and ultimately "intervene in the world" (p. 45). To further inform the methodological and pedagogical processes in this study, Indigenous-specific perspectives were applied to the YPAR and critical media production approaches. Specifically, McCarty and Lee (2014) call for Culturally Sustaining/Revitalizing Pedagogy (CSRP) to purposefully reinvigorate traditional Indigenous knowledges. Central to CSRP is the importance of accountability to communities and tribal nations.

Pedagogically and methodologically, Indigenous storywork, which emphasizes "story as method" and the interrelatedness of knowledge, storytellers, and community members (Archibald, 2008), served as a guiding theory for both the youth-led projects and our study of the surrounding processes. Indigenous storywork includes attention to the principles of respect, responsibility, reciprocity, reverence, holism, interrelatedness, and synergy throughout the processes of developing, interpreting, and sharing stories and histories (Archibald, 2008). Furthermore, Indigenous storywork acknowledges the importance of listening with "three ears"- "two that we hear with and the one in our heart" (Archibald \& Parent, 2019, p. 14). 


\section{Methods}

In addition to Indigenous storywork, this project combines case study (Creswell, 2009; Stake, 1995) and participatory methods (Northway, 2010) to cultivate in-depth, collaborative, and bounded analysis of youth-led research and critical media production. Two communities-one on the Piikani (Blackfeet) reservation and one on the Apsáalooke (Crow) reservation-provided unique geographic and cultural contexts central to investigating these topics. A Predominantly White University (PWI) (Willie, 2003) located at a distance from the reservation communities provided an additional research context. While the projects under study are part of a larger program, which has been operating for over six years, the examples highlighted in this paper occurred primarily over the course of three years (2016-2019). The PWl's Institutional Review Board (IRB), as well as the Blackfeet Nation IRB (BNIRB), reviewed and approved the research described in this article. We note that these IRBs are distinct and that the BNIRB and other tribal IRBs operate as part of sovereign nations with unique requirements, timelines, and processes before, during, and after research. For example, the BNIRB requires approved researchers to present results annually to the community during the Days of the Piikani research showcase. However, not all Indigenous nations have IRBs and not all non-tribal IRBs require approval from Indigenous nations, although we argue that they should. In the case of this study, the PWI's IRB requires tribal IRB prior to PWI IRB approval.

\section{Positionality}

In addition to adhering to tribal IRB protocols, research that strives to advance IRMs requires critical self-location work, reflection on relationships and power structures, and recognition of the importance of sustained partnerships. As a research team, we came to storywork as a methodology/pedagogy-and to these projects in particular-through multi-year collaborations.

Over six years ago, Christine met Brad while learning about how he supported his Piikani high school students' research of artifacts recently repatriated to the tribe. We began to co-develop a youth-led filmmaking model to help document that research. Two years ago, Veronica approached our team to discuss partnering with youth in the Apsáalooke community. Our leadership team has also included additional faculty, students, and graduates with expertise in film studies, Native American Studies, and multicultural education. Below, we describe our individual journeys to this partnership in more depth.

I (Christine) am a 44-year-old white woman who is an outsider in both Piikani and Apsáalooke communities. Given my identity, I am more a learner than a researcher in this case study. My background with the Piikani community is especially complex, since my family settled on land stolen from the Blackfeet Nation only a few generations ago. My grandmother was born and raised in the same town where Brad's great-grandfather was forced to board a train bound for Carlisle Indian School in Pennsylvania. Despite my family's historical proximity to Piikani communities, my relatives shared little about their understanding of 
Indigenous experiences, and I only remember a handful of times teachers shared information about Indigenous peoples during my K-12 education. As a teacher, scholar, and teacher educator, I have spent most of my career working with and learning from Indigenous community partners across the West. Today, I work at the PWI featured in this study, where I continue learning about Indigenous experiences and social justice education from mentors both at and beyond the university. Given my positionality as a learner, community outsider, nonIndigenous scholar, and member of the digital storywork leadership team, implementing participatory and collaborative analyses proved integral to the research design for this case study.

\section{Oki nii-st-oo nii-taa-niiko Omak Saa-koo-ma-pi... Amp-skaa-pi} Piikani. I (Brad) was raised on the Blackfeet Indian Reservation in Montana. Therefore, my life experiences are grounded in my worldview as an Amp-skaa-pi Piikani. My great-uncle gave me the name Omak Saa-koo-ma-pi, which in English means "Big Boy," and which was previously held by my late grandfather. For many Indigenous peoples, recognition of relationality and the process of naming serves to identify an individual who is expected to commit—spiritually and collectively - to their family, community, and nation. Piikani names also provide metaphorical guidance for one's life. In my case, my name encouraged me to devote my attention to Piikani history and educational systems.

As a high school social studies teacher in a school on my reservation, I created my own curriculum, as texts were not reflective of or relevant to the experiences, perspectives, and culture of the Piikani people. Ultimately, I left the school to take a position at a tribally-chartered college, whose mission specifically outlines a commitment to "integrating Blackfeet language and culture" into courses, programs of study, and student services. Completion of my doctorate in educational leadership required me to further acknowledge intersections and tensions between Piikani ways of knowing and mainstream "normative practices" of the academy (Kovach, 2013, p. 115). My main goal, as an educator, researcher, and Piikani person, is to ensure the transfer of Piikani knowledges to the next generation of Piikani researchers. I also take seriously Indigenous oversight of all teaching and learning throughout Indian Country. A central expectation for such work is the involvement of Indigenous community members and adherence to cultural protocol throughout research and education processes. Currently, I work at a PWI as the Tribal Outreach Specialist.

Within many Indigenous communities, contextualizing oneself within relationships is an essential aspect of self-location and introduction. I (Veronica) am Diné (Navajo) of the Many Hogans Clan, and born of the Mexican Clan. My maternal grandparents are the Tangle Clan and my paternal grandparents are the Bitter Water Clan. I earned bachelor's degrees in History and Race and Ethnic Studies. As is true in many rural and tribal communities, I wear many hats. I am the Director of the Crow Consortium of $21^{\text {st }}$ Century Community Learning Centers, Implementation Specialist for the state's Office of Public Instruction, a School Training and Technical Assistance Specialist for the National Native Children's Trauma Center, and the Co-Advisor for the Arrow Creek UNITY (United National 
Indian Tribal Youth) Council. At a state conference, I met with Christine and Brad to learn about ways to bring digital storywork to Apsáalooke youth at the school where, at the time, I was serving as the After School Program Coordinator for the $21^{\text {st }}$ Century Community Learning Center.

\section{Context and Participants}

Archibald and Parent (2019) draw upon a definition articulated by the Canadian Institutes of Health Research to describe community as a "collectivity with shared identity or interests" (p. 11). To extend upon this, Gruenewald (2003) emphasizes that while a sense of community is often informed by a collective place-consciousness, it is more than a physical place. Indigenous communities are unique and diverse, with each one "distinguished by its own language, customs, religion, economy, historical circumstances, and environment" (Lomawaima, 2004, p. 442). The communities included in this case study are quite different, emerging from distinct language families, traditions, and histories.

In the Apsáalooke context, 12 youth (11 high school students and one middle school student), who all identify as Indigenous, conducted communitybased research and worked to create short films as part of an after-school club. Additional community partners included elders, cultural and tribal government leaders, educators, and program directors. Within the Piikani community, participants included seven students attending an alternative high school or tribal college, as well as faculty and staff from the high school and tribal college, elders, and community leaders. All of the students and most of the community members (with the exception of four of the alternative high school teachers and staff) identify as Piikani. Piikani student participants were eligible for high school or college credit, and three peer leaders (two tribal college students and one high school student) received stipends and additional support to provide community-based mentorship for other participants.

PWI participants included undergraduate and graduate students studying filmmaking, education, and/or Native American Studies; film and education faculty; and recent graduates working in the film industry. Most PWI participants identified as non-Indigenous, and many had limited understandings in terms of Indigenous knowledges and ways of knowing prior to involvement with the project. PWI students and recent graduates earned independent studies credit and/or received stipends for providing technical mentorship. Additionally, in both Indigenous communities and at the PWI, content and skills developed during project activities were integrated into formal and informal educational contexts spanning multiple humanities and social science subjects, as well as K-8 and 5-12 social studies methods courses for pre-service teachers.

Participants engaged in a series of half-day workshops, three of which were based in each community and two of which were held at the PWI. The first workshop included research preparation (e.g., learning about Apsáalooke or Piikani research protocol, selecting topics and participants, developing research questions, etc.), as well as basic filmmaking and interviewing techniques (e.g., 
camera setup, asking "softball" questions, etc.). During the second workshop, participants practiced using equipment (e.g., completing a technical skills scavenger hunt), developed storyboards, and began collecting interview and observational data. The next workshops were held at the PWI, where students had access to the university's production studio and editing labs. These workshops included discussions about cultural protocol and related technical challenges, troubleshooting, and editing. A final workshop focused on final editing in preparation for community showcases and screenings. By the end of the workshop series, teams had either completed films or "trailers" focusing on their topics. In the Apsáalooke community, trailers were shared during a basketball tournament in the community. Films produced by the Piikani participants have been screened for community members and shared on YouTube.

Indigenous students and community leaders made all major research and filmmaking decisions, while PWI participants provided technical assistance, both in terms of general research practices (e.g., ideas for developing interview questions) and filmmaking skills (e.g., how to use "b-roll"). Typically, this assistance was provided as part of a menu of options (e.g., "here are several approaches to interviewing"), and Indigenous researchers remained responsible for making final decisions that aligned with their vision and community expectations. Indigenous community members and educators also collaborated with PWI project leaders to plan, facilitate, and evaluate workshops and projects.

In both the Piikani and Apsáalooke communities, participants initially planned to explore a wide variety of topics, including the effects of substance abuse on extended families, the life history of an "Indian Cowboy" inducted into the Rodeo Hall of Fame, and personal stories from boarding school survivors. However, in both contexts, participants decided to shift from individual projects to more collective efforts after they began working with community members. Together, Piikani participants created the film Full Circle, which introduces the importance of sustaining and revitalizing Piikani history, culture, and language. A second Piikani project, Bear River, focuses on commemoration of an 1870 massacre that resulted in more than 200 Piikani deaths. For both of these examples, data collection included interviews with community leaders and footage of significant sites (e.g., Chief Mountain, the ceremonial room at the tribal college, the site of the massacre).

In the Apsáalooke context, small groups began working on separate films all focusing on traditional use of tobacco for prayer and ceremony in juxtaposition with conventional, mainstream abuse (i.e., chewing, smoking). After initial footage had been collected, the groups naturally began to work together to share data and resources. For example, students shared footage of sacred sites in the Pryor Mountains and tobacco offerings in a local park.

\section{Data Sources and Analysis}

Although sharing topics selected by participants helps contextualize examples in this article, this case study focuses on the process of digital storywork 
as pedagogy and methodology, and we note that the specific content of the projects belongs to the youth researchers and their communities, not the coauthors. Multiple data sources contributed to the study of the storywork process, including planning resources (e.g. workshop agendas, research and filmmaking guides), interviews with participants and educators, social media discussions and posts, artifacts from workshops (e.g., storyboards/treatments, interview protocol planning documents, film clips), and researcher memos and field notes. These data were analyzed in four interconnected, iterative, and participatory phases: (a) in-vivo open coding (Emerson, Fretz, \& Shaw, 1995; Rubin \& Rubin, 2005; Strauss, 1987), (b) collaborative coding with student filmmakers (Stanton, Hall, \& Ricciardelli, 2016), (c) "participatory sense-making" (De Jaegher \& Di Paolo, 2007, p. 485), and (d) focused coding to align results with storywork values identified by Indigenous communities (Archibald, 2008).

The initial phase of analysis occurred simultaneously with or immediately following data collection. To center the participatory and youth voice elements of the study's design and the overarching goal of the storywork partnership, this phase employed in-vivo open coding, which used direct quotes from participant interviews and observations to describe key themes from segments of data. Members of the research team then verified selection of quotes and themes with community partners. This aspect proved particularly valuable as community members were able to provide context- and tribally-specific clarification in terms of importance and intent of several of the identified quotes.

The central participatory element of this study, collaborative coding, happened concurrently with the student-led data collection and film editing. During this phase, students engaged cooperatively with peers, educators, and community members in analysis of data they collected or created, such as archival photographs, interviews, and their own film artifacts. Although the process varied by context, participant age, and project topic, the analysis was consistently informed by robust knowledge systems held collectively by the unique communities. For example, for their film on language revitalization, Piikani participants organized audiovisual data according to several themes identified as important by the community (e.g., "Remember Our Past, Build Our Future"). However, within the processes of collaborative interpretation, there remained opportunity for creativity and diversity. For instance, while all three Apsáalooke teams decided to include images of places where tribal members engage in ceremonial tobacco use, the specific spaces highlighted in each team's film varied.

The third component of data analysis emphasized collective interpretation through what De Jaegher and Di Paolo term "participatory sense-making" (2007, p. 485). During planning and debriefing sessions, members of the research team engaged in dialogue with each other, with student participants, and with community leaders in order to prioritize the dynamism of participatory research and meaning making, particularly in contexts where diverse epistemological paradigms, perspectives, and activities interact. For example, interpretations of data varied due to a co-researcher's age, education, cultural identity, and familiarity with traditional and community-specific knowledges. This phase extends beyond 
conventional notions of credibility and member checking in its attention to generate and transform meaning through "the interplay between the unfolding interaction process and the individuals engaged in it" (De Jaegher \& Di Paolo, 2007, p. 485). Such interaction can inform purposeful "coordination" of understanding as long as there is an "explicit and focused attention to [the] relational domain" between individuals and activities (De Jaegher \& Di Paolo, 2007, p. 494). In the study described in this paper, participants frequently acknowledged the influence of positionality and relationality on understanding. For example, through several sense-making sessions, team members noted that it was necessary to reach out to elders or other leaders to ensure responsible interpretation.

As a final step in the analysis, focused coding practices aligned results with seven storywork values (Archibald, 2008): holism, respect, interrelatedness, responsibility, reverence, synergy, and reciprocity. Archibald (2008) describes holism as "the interrelatedness between the intellectual, spiritual..., emotional, and physical" aspects of identity (p. 11). Respect requires deep listening through simultaneous activation of all of these aspects (Archibald \& Parent, 2019). Interrelatedness refers to acknowledgement of relationships between peoples and also between oneself and the story being shared (Archibald, 2008; Archibald \& Parent, 2019). Similarly, Archibald (2008) explains that storywork relies upon synergy —or a dynamic participation — between both storyteller and listener. Within Indigenous research, this participation requires an active role in the appropriate sharing of knowledge (Windchief \& San Pedro, 2019). As Archibald and Parent (2019) note, such a responsibility invokes a "hands back, hands forward" effort, where scholars "reach back to receive teachings" from the past while simultaneously passing those teachings forward to the next generation (pp. 4-5). Archibald and Parent (2019) note that to appreciate the full meaning of a story, listeners need to demonstrate reverence for both the knowledge itself and knowledge carriers in personal and spiritual ways. Finally, Archibald and Parent (2019) describe the importance of reciprocity, or "giving-back" to the community, in order to sustain and revitalize cultural knowledges (p. 6).

\section{Results and Discussion}

Broadly, the storywork projects demonstrated potential to advance Archibald's (2008) storywork values (i.e., holism, respect, interrelatedness, responsibility, reverence, synergy, and reciprocity), particularly in terms of representing Indigenous experiences and perspectives, promoting civic engagement for/with Indigenous youth, and supporting dialogue and critical media education across diverse groups. Below, we highlight pedagogical and methodological results from the case study.

"Learn the Higher Level of Cultural Knowledge": Advancing Holistic and Respectful Understandings of Indigenous Experiences 
Overall, the digital storywork process emphasized critical thinking about Indigenous knowledge and ways of knowing. For example, the after-school program coordinator in the Apsáalooke context noted, "Many of the other programs we've been doing are more the arts and crafts, but this project gets [youth] to learn the higher level of cultural knowledge." This deeper and more holistic awareness of cultural knowledge led to students wanting to create projects that tell real stories without relying on the "shock factor" prevalent in many documentary films about reservation life. Similarly, Piikani participants discussed the challenges of balancing authentic representations with positive, respectful, and strengths-based messages. As one Piikani student explained, responsibility also requires individuals to "come to terms with their identity"-and the larger social expectations and assumptions associated with that identity-in order to challenge stereotypes about Indigenous peoples.

During the initial workshops and conversations, participants brainstormed topics encompassing holistic community interests such as health, leadership, histories, language use, and mythologies. A non-Indigenous student from the PWI noted that the proposed topics were powerful, complex, and relevant to the broader community in a way that is seldom true for white filmmakers. These topics supported robust learning about geography (e.g., sacred sites), government (e.g., community event planning), history (e.g., the Bear River/Marias River Massacre), and economics (e.g., costs of tobacco use). While mainstream education is well known for fragmented learning that isolates and separates subject matter, the storywork projects embraced the holistic and complicated relationships between content, individuals, and places.

In both contexts, students discovered that complex cultural protocol restricts when, how, and with whom certain traditional knowledges can be shared. For example, as Piikani students considered ways to break up interviews for a more visually appealing effect, they discussed weaving segments of a song throughout an elder's account. However, the participants learned that dividing a song that had been "gifted" to the group would be disrespectful, since traditionally neither song nor story would be fragmented. The conversation resulted in a plan to consult additional leaders prior to and throughout editing processes. Similarly, the Apsáalooke youth acknowledged that while they could film places where ceremonies that include tobacco offerings are made, it would not be respectful to film the ceremonies themselves.

\section{"Keep it Sacred": Promoting Responsibility and Reverence through Civic Engagement}

One of the most promising results of digital storywork is its potential to support student-centered pedagogy and civic engagement. While student researchers made all major decisions regarding research topics, film editing, and goals for their research, these decisions were always grounded within the needs of the broader Apsáalooke and Piikani communities. Furthermore, the participants recognized a larger, collective sense of responsibility, particularly to younger 
generations. For example, the Apsáalooke researchers emphasized their desire to provide meaningful educational materials for elementary-aged students, and the Piikani researchers noted a goal to develop resources for both $\mathrm{K}-12$ and postsecondary settings.

Project leaders and participants noted high levels of engagement throughout the projects, due in large part to students' common interest surrounding filmmaking and audiovisual media. The number of Apsáalooke students involved in the digital storywork projects represented more than a third of the total school population, which is especially impressive for a high school extra-curricular program. The combination of engaging pedagogy and a critical mass also encouraged students to take risks that would have been less likely in more typical teacher-centered contexts. For example, while the Apsáalooke youth were initially hesitant to begin organizing their audiovisual data during film editing, the atmosphere changed after the adults and all PWI participants left the room. In a short period of time, each team had developed a storyboard and started organizing footage. Similarly, a Piikani participant described research and media production as a "new dream I didn't even know I had." Several participants have applied technical skills learned beyond the digital storywork projects. For example, one Piikani participant contributed footage to a local TV newscast. In this example, the filmmaker-researcher noted a sense of responsibility to "share our stories" through accurate and strengths-oriented representations of her community.

Student researchers also learned the importance of balancing enthusiasm and engagement with reverence throughout Indigenous research and storywork. For example, while students wanted their products to be entertaining, they also recognized the need to, according to an Apsáalooke student, "keep it sacred!" Workshops in both communities frequently addressed the responsible sharing of knowledge surrounding sacred places and stories. Project leaders, participants, and youth wrestled with the dichotomy of disseminating Indigenous knowledge and protecting that knowledge from misappropriation or commodification. As a result of these discussions, participants recognized that reverence requires careful navigation of both cultural knowledge and individual needs. For example, one Piikani student suggested that using artistic representation to share the Bear River massacre could encourage collective healing. However, another team member argued that "with a massacre, there can never really be healing." As they collected data, the team encountered similar tensions within the community, with some community members encouraging the film's production as a way to confront historical trauma while others simply desired to "just move on from that [horrible event]." Similarly, Archibald and Parent (2019) note, "The concept of reverence is very personal and subjective" (p. 6).

An awareness of the importance and complexity of responsibility and reverence in research extended well beyond basic selection of topics, and students in both contexts emphasized the importance of sharing the stories "in a good way." For example, members of one Piikani team spent extensive time discussing an interview they were concerned might offend elders. Although they felt compelled to accurately document the speaker's words and ideas, they also recognized their 
responsibility to honor community values, which include a reverence for elders. Specific to editing of digital stories and interviews, Indigenous scholars Iseke and Moore (2011) emphasize the need for a "kinship responsibility" that acknowledges the broader community's belief systems and experiences (p. 33).

\section{"The Students Have to Really Learn What to Do": Generating Interrelatedness and Synergy through Dialogue}

Indigenous storywork requires an active collaboration between storytellers (e.g., elders, knowledge carriers, other experts and leaders) and those hearing the story (Archibald, 2008). Within both communities, student researchers and community members expressed a belief that filmmaking is a form of living oral history, since it allows the viewer to see and hear the storyteller. For example, a Piikani student described digital storywork as a "culturally valid" model, suggesting that "film has a more powerful impact [than written text]" given its potential to "recreate the oral tradition." Other participants, leaders, and elders agreed that audiovisual media better supports the idea of interrelatedness than written text, since film allows learners to see and hear the storytellers. For example, a Piikani participant explained, "[It] becomes more personal when you see the person telling the story. It's different from reading a book, where you can't see the person." Similarly, Iseke and Moore (2011) argue, "Indigenous digital storytelling challenges not only the stories of the dominant society but also opposes the exclusivity of textbased resources" (p. 34).

Furthermore, the storywork process led to new understandings about the nature of relationships between youth and community members. For example, the program coordinator noted that an Apsáalooke elder used to believe all youth were disinterested in culture, but through involvement with the project, she realized that the students simply lacked exposure to cultural protocol. Through an emerging awareness of interrelatedness, youth researchers recognized the importance of developing and sustaining dialogue with a variety of elders, leaders, and educators in order to ensure adherence to community expectations (e.g., who to talk to, how to talk with them, how to represent them, where to film, what to film, etc.). As the program coordinator explained, "Elders are always saying they want young people to learn this, but they also don't want the knowledge shared just however, so the students have to really learn what to do." Similarly, participants interacted with each other in ways that suggested increasing awareness of self-location within and beyond the specific Indigenous community. For example, a Piikani high school student expressed concerns about not knowing any elders well enough to interview them. This recognition led to a community member offering to "introduce" the student to elders.

Relatedly, participants learned that respectful research requires ongoing discussions with knowledge carriers. For many participants, this understanding generated anxiety about how to build relationships, since only a few students had strong pre-existing connections to cultural leaders. One Piikani youth noted that while she comes from a very strong family with positive relationships, her biological 
grandparents have passed away, and she does not have relationships with other "grandparents" in the community who can teach her about cultural knowledge. To learn about this knowledge, as well as the cultural protocol for accessing it, this student partnered with a tribal college student who had established relationships with several elders. As Iseke and Moore (2011) note, inter- and multi-generational storywork can be a powerful approach for culturally responsive education.

Storywork also creates space for synergistic integrations that honor traditional ways of knowing. For example, a Piikani youth emphasized that while "fact" and "fiction" can blur in retellings of Indigenous histories, such retellings have a central purpose to share knowledge in order to solve real world problems, as opposed to merely serving as entertainment. PWI participant involvement also provided opportunities for explicit dialogue about cultural protocol and integration of technical and cultural knowledge. For instance, as a PWI technical consultant discussed different camera angles, several Apsáalooke youth noted it would not be appropriate to use a high angle shot (i.e., one that makes the subject appear physically smaller) for interviews with elders. This recognition led to dialogue about expected interactions between elders and youth, as well as discussion about the audience(s) that might access the research results (e.g., Will this film be shared with non-Indigenous peoples? What are the ages of potential viewers? How can we find out more about appropriate representations of these stories?)

\section{Significance and Implications: Advancing Reciprocity}

Archibald's (2008) seventh value, reciprocity, is central to the findings described in this article. Historically, schools across the U.S. have marginalized or excluded minoritized knowledges and ways of knowing, and today's educational efforts continue to fall short in terms of working with communities of color. Teachers are often ill-equipped and/or uncomfortable with confronting curricular (mis)representations, and they also have limited experience with pedagogical strategies that can encourage critical thinking, civic dialogue, and learning for social justice (King \& Chandler, 2016; Knowles, 2018). Without the guidance of curricular counter-narratives and pedagogical models, the predominantly white teachers in today's schools typically practice "racial silence" (Ladson-Billings, 2003 , p. 8) instead of creating space for expanded accuracy, critical thinking, and their own learning. As the findings from this study demonstrate, student-led critical media research and production-and digital storywork specifically-can create opportunities to serve students and communities by generating curricular counternarratives, facilitating critical student-centered pedagogy, and-perhaps most importantly-transforming the role of the teacher to that of a co-learner.

Digital storywork promotes reciprocal partnerships, intercultural learning, and intergenerational collaboration-components that are vital for the democratization of social studies education. Through their research, participants realized that while representations of Indigenous experiences produced by nonIndigenous peoples have long been disrespectful, given the settler fascination with the "vanishing Indian" (King, 2015, p. 23), constructing digital counter-narratives 
can be a way to engage within community and transform educational spaces. Similarly, the participants recognized the urgency of sharing these counternarratives, as tied to education (including teacher education) and collective healing. As one Piikani participant noted,

We're at a crucial time. We're risking the loss of our language and our culture. This [project] comes at the right time to point us in the right direction for healing. Instead of carrying all that baggage by yourself, [hearing the stories of others] lightens your load.

The results also affirm research that suggests intercultural dialogue is enhanced through student-centered pedagogy and ensuring a critical mass of students of color (Achinstein et al., 2010). Educators often resist teaching about content they perceive to be controversial, particularly that which conflicts with their ideologies (Knowles, 2018). The results of this case study suggest the potential for digital storywork to support Indigenous student-led teaching that encourages learning for white educators, scholars, and peers. Similarly, this study illustrates ways that digital storywork and youth-led research can support two-way intergenerational learning (e.g., elders learned that the youth are not disrespectful, just uninformed; youth learned about the complexities of cultural protocol).

Additionally, the results suggest that audiovisual media, when synthesized with IRMs, Indigenous storywork, and youth-led research, can advance technical and critical literacy. In particular, this case study demonstrates the potential for digital storywork to advance the democratization and (re)Indigenization of education, particularly in terms of elevating voices of Indigenous youth. Throughout digital storywork, participants are expected to be active "citizens"-of the U.S. and of their sovereign nations-by engaging in responsible data collection, analysis, and dissemination of audiovisual counter-narratives. Therefore, the projects described in this paper provided opportunities to reenvision the definition of "citizenship" in terms of sovereign nations like those of the Apsáalooke and Piikani peoples. Although the projects highlighted in this article are not fully-realized examples of Youth Participatory Action Research since they do not require an "action" component to solve a community problem, they offer insights regarding the importance of powerful and effective youth-led decision-making within social studies education and research. Digital storywork engages students in original media-based research, allowing them to go to the root of the information instead of relying on secondary, tertiary, or fake sources. In particular, Caraballo, Lozenski, Lyiscott, and Morrell (2017) emphasize the potential for youth-led research, such as YPAR, to support rigorous learning. Despite its successes, however, youth-led research remains understudied within educational research literature.

As a research team, we acknowledge the many power differentials that persist in schools, universities, and research due to historical trauma, oppression, and racism, and we note that teams that strive to integrate IRMs with YPAR need to go beyond views of reciprocity that are decontextualized from broader histories of schooling in the U.S. In particular, storywork offers an opportunity to confront 
inequities by centering the experiences of communities and youth that have typically been marginalized.

Digital storywork provides powerful opportunities for educators, scholars, community members, and students to learn about community knowledges and ways of knowing. Broadly, Indigenous storywork (Archibald, 2008), and more specifically digital Indigenous storywork as presented in this article, offers a framework to support youth and community leaders in making practical, methodological, and pedagogical contributions to K-12 education, YPAR, and IRMs. In particular, when integrated with YPAR, storywork provides an opportunity to reposition youth and their stories, elevate attention to the role of audiovisual media - and critical media literacy — in learning, and contextualize TribalCrit tenets within specific community contexts and classrooms. For many Indigenous peoples, stories serve as "meaningful, theory-full practice" that sustains and revitalizes cultural and collective understandings (King, Gubele, \& Anderson, 2015, p. 9). In other words, storywork can extend beyond the collection, interpretation, and dissemination of oral histories and documentary stories to also recognize the way the stories are theorized, told, heard, and shared (Archibald, 2008; Brayboy, 2005). True reciprocity hinges upon accountability to the communities-and youth within those communities-and student-led research such as digital storywork offers a path for such efforts.

\section{Notes}

1. To enact critical methodology and pedagogy, scholars and educators recommend using identifiers preferred by specific Indigenous communities (e.g., Crow, Blackfeet). However, such usage can be complicated, since individuals within those communities may not identify using the majority affiliation and/or they may prefer a more general term (e.g., Native). Additionally, broad scale action may be best advanced through use of a collective term, particularly one that is widely affirmed by scholars and leaders (e.g., Indigenous). Throughout this paper, we use various terms deemed appropriate for specific contexts by Indigenous partners and mentors. Furthermore, we defer to these partners for advice regarding specific spellings of traditional names (e.g., Apsáalooke, Piikani).

2. We use lower case for "white" as a means to draw attention to Indigenous peoples and groups and reduce-or at least question-power associated with white peoples and groups.

\section{References}

Achinstein, B., Ogawa, R.T., Sexton, D., \& Freitas, C. (2010). Retaining teachers of color: A pressing problem and a potential strategy for "hard-to-staff" schools. Review of Educational Research, 80(1), 71-107.

Archibald, J. (2008). Indigenous storywork: Educating the heart, mind, body, and spirit. UBC Press. 
Archibald, J., \& Parent, A. (2019). Hands back, hands forward for Indigenous storywork as methodology. In S. Windchief \& T. San Pedro (Eds.), Applying Indigenous research methods: Storying with peoples and communities (pp. 3-20). Routledge.

Bautista, M., Bertrand, M., Morrell, E., Scorza, D. \& Matthews, C. (2013). Participatory action research and city youth: Methodological insights from the Council of Youth Research. Teachers College Record, 115(100303), 123.

Beattie, H. (2012). Amplifying student voice: The missing link in school transformation. Management in Education, 26(3), 158-160.

Brayboy, B. (2005). Toward a tribal critical race theory in education. The Urban Review, 37(5), 425-446.

Cammarota, J., \& Fine, M. (2008). Youth participatory action research: A pedagogy for transformational resistance. In J. Cammarota \& M. Fine (Eds.), Revolutionizing education: Youth participatory action research in motion (pp. 1-11). Routledge.

Caraballo, L., Lozenski, B. D., Lyiscott, J. J., \& Morrell, E. (2017). YPAR and critical epistemologies: Rethinking education research. Review of Research in Education, 41, 311-336.

Creswell, J. W. (2009). Research design: Qualitative, quantitative, and mixed methods approaches ( $3^{\text {rd }}$ ed.). Sage.

De Jaegher, H., \& Di Paolo, E. (2007). Participatory sense-making: An enactive approach to social cognition. Phenomenology and the Cognitive Sciences, 6, 485-507.

Emerson, R. M., Fretz, R. I., \& Shaw, L. L. (1995). Writing ethnographic fieldnotes. University of Chicago Press.

González, N., Moll, L. C., \& Amanti, C. (2005). Funds of knowledge: Theorizing practice in households, communities, and classrooms. L. Erlbaum Associates.

Grande, S. (2008). Red pedagogy: The un-methodology. In N. K. Denzin, Y. S. Lincoln, \& L. T. Smith (Eds.) Handbook of critical and Indigenous methodologies (pp. 233-254). Sage.

Gruenewald, D. A. (2003). Foundations of place: A multidisciplinary framework for place-conscious education. American Educational Research Journal, 40(3), 619-654.

Haag, A. M. (2007). The Indian Boarding School era and its continuing impact on tribal families and the provision of government services. Tulsa Law Review, 43(1), 149-168.

Hall, B. (2018). Piikani school leadership (Doctoral dissertation). Retrieved from ERIC database (ED591228). 
Hixon, W. (2013). American settler colonialism: A history. Palgrave McMillan.

Iseke, J., \& Moore, S. (2011). Community-based Indigenous digital storytelling with elders and youth. American Indian Culture and Research Journal, 35(4), 19-38.

King, L. (2015). Sovereignty, rhetorical sovereignty, and representation: Keywords for teaching Indigenous texts. In L. King, R. Gubele, \& J. R. Anderson (Eds.), Survivance, sovereignty, and story: Teaching American Indian rhetorics (pp. 17-34). The University Press of Colorado.

King, L. J., \& Chandler, P. T. (2016). From non-racism to anti-racism in social studies teacher education: Social studies and Racial Pedagogical Content Knowledge. In A. R. Crowe \& A. Cuenca (Eds.), Rethinking social studies teacher education in the twenty-first century (pp. 3-21). Springer.

Knowles, R. T. (2018). Teaching who you are: Connecting teachers' civic education ideology to instructional strategies. Theory \& Research in Social Education, 46, 68-109.

Kovach, M. (2009). Indigenous methodologies: Characteristics, conversations, and contexts. University of Toronto Press.

Kovach, M. (2013). Treaties, truths, and transgressive pedagogies: Re-Imagining Indigenous presence in the classroom. Socialist Studies, 9(1), 109-127.

Ladson-Billings, G. (1999). Preparing teachers for diverse student populations: A critical race theory perspective. Review of Research in Education, 24, 211247.

Ladson-Billings, G. (2003). Lies my teacher still tells: Developing a critical race perspective toward the social studies. In G. Ladson-Billings (Ed.), Critical race theory perspectives on social studies (pp. 1-11). Information Age Publishing.

Loewen, J. W. (2010). Teaching what really happened: How to avoid the tyranny of textbooks and get students excited about doing history. Teachers College Press.

Lomawaima, K.T. (2004). Educating Native Americans. In J.A. Banks \& C.A. McGee Banks (Eds.), Handbook of research on multicultural education ( $2^{\text {nd }}$ ed.) (pp. 441-461). Jossey-Bass.

McCarty, T., \& Lee, T. (2014). Critical culturally sustaining/revitalizing pedagogy and Indigenous education sovereignty. Harvard Educational Review, 84 (1), 101-1

Mitra, D. L. (2008). Amplifying student voice. Educational Leadership, 66(3), 2025.

Morrell, E., Duenas, R., Garcia, V., \& Lopez, J. (2013). Critical media pedagogy: Teaching for achievement in city schools. Teachers College Press. 
Northway, R. (2010). Participatory research: Part 1: Key features and underlying philosophy. International Journal of Therapy and Rehabilitation, 17(4), 174179.

Ostler, J. (2004). The Plains Sioux and U.S. colonialism from Lewis and Clark to Wounded Knee. Cambridge University Press.

Paris, D. (2012). Culturally sustaining pedagogy: A needed change in stance, terminology, and practice. Educational Researcher, 41(3), 93-97.

Rubin, H., \& Rubin, I. (2005). Analyzing coded data. In H. Rubin \& I. Rubin, Qualitative interviewing: The art of hearing data ( $2^{\text {nd }}$ ed.) (pp. 224-245). SAGE.

Russell, W. B. (2010). Teaching social studies in the $21^{\text {st }}$ century: A research study of secondary social studies teachers' instructional methods and practices. Action in Teacher Education, 32(1) 65-72.

Sabzalian, L. (2019). The tensions between Indigenous sovereignty and multicultural citizenship education: Toward an anticolonial approach to civic education. Theory \& Research in Social Education, 47(3), 311-346. doi: 10.1080/00933104.2019.1639572

Sanchez, T. R. (2007). The depiction of Native Americans in recent (1991-2004) secondary American history textbooks: How far have we come? Equity \& Excellence in Education, 40(4), 311-320.

San Pedro, T. (2015). Silence as weapons: Transformative praxis among Native American students in the urban Southwest. Equity \& Excellence in Education, 48(4), 511-528.

Shear, S. B., Knowles, R. T., Soden, G. J., \& Castro, A. J. (2015). Manifesting destiny: Re/presentations of Indigenous peoples in K-12 U.S. history standards. Theory \& Research in Social Education, 43(1), 68-101.

Smith, L. T. (1999). Decolonizing methodologies: Research and Indigenous peoples. Zed Books.

Stake, R. E. (1995). The art of case study research. SAGE.

Stanton, C. R. (2014). The curricular Indian agent: Discursive colonization \& Indigenous (dys)agency in U.S. history textbooks. Curriculum Inquiry, 44(5), 649-676. doi: 10.1111/curi.12064

Stanton, C. R., Hall, B., \& Ricciardelli, L. (2016). Cross-Cultural digital storywork: Striving for Indigenous sovereignty with/in communities. The Engaged Scholar Journal, 2(1), 247-265.

Strauss, A. L. (1987). Qualitative analysis for social scientists. Cambridge.

Tuck, E., \& Yang, K. W. (2013). Youth resistance research and theories of change. Taylor \& Francis.

Willie, S. (2003). Acting Black: College, identity, and the performance of race. Routledge. 
Wilson, S. (2008). Research is ceremony: Indigenous research methods. Fernwood Publishing.

Windchief, S., \& San Pedro, T. (2019). Preface: Reflection, action, and conscientization. In S. Windchief \& T. San Pedro (Eds.), Applying Indigenous research methods: Storying with peoples and communities (pp. xiv-Xxv). Routledge.

\section{Author Contact}

Christine Stanton, christine.rogers1@montana.edu

Department of Education

Montana State University

P.O. Box 172880

Bozeman, MT 59717-2880

Brad Hall, bradford.hall@mso.umt.edu

Payne Family Native American Center

University of Montana

32 Campus Drive

Missoula, MT 59812

Veronica Willeto DeCrane, Veronica.Willeto@mso.umt.edu

Room 211, Phyllis J. Washington College of Education

University of Montana

32 Campus Drive

Missoula, MT 59812 